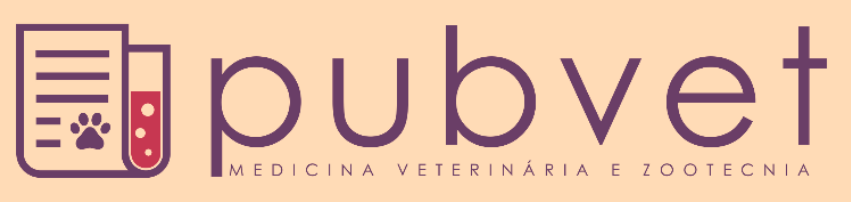

https://doi.org/10.31533/pubvet.v13n8a388.1-7

\title{
Desenvolvimento, avaliação físico-química e microbiológica da farinha de tambaqui, Colossoma macropomum (Cuvier, 1818)
}

\author{
Lindalva de Melo Ferreira da Costa ${ }^{1}$, Ana Célia Vasconcelos Lages ${ }^{1}$, Jaqueline Freitas do \\ Nascimento $^{2}{ }^{\circ}$, Anne do Socorro Santos da Silva ${ }^{30}$, Antonio Carlos Souza da Silva Júnior ${ }^{3 *} \bullet$ \\ ${ }^{I}$ Nutricionista, Instituto Macapaense de Ensino Superior-IMMES. Macapá-AP Brasil. \\ ${ }^{2}$ Acadêmica de Farmácia, Instituto Macapaense de Ensino Superior-IMMES. Macapá-AP Brasil \\ ${ }^{3}$ Pesquisador(a) do Instituto de Pesquisas Científicas e Tecnológicas do Estado do Amapá, Núcleo de Ciência e Tecnologia de Alimentos. Macapá-AP Brasil. \\ *Autor para correspondência,E-mail:jr_bio2005@yahoo.com.br
}

\begin{abstract}
Resumo. A carne de pescado é a fonte proteica de origem animal mais consumida no mundo. Na região Norte o consumo é cerca de $135 \mathrm{~kg}$ per capita/ano. A farinha de peixe, mesmo sendo pouco conhecida e utilizada em todo o território brasileiro, vem sendo aos poucos descoberta pelos nutricionistas e seguidores de alimentação saudável. Este trabalho tem como objetivo avaliar as características físico-químicas e microbiológicas de uma farinha proteica desenvolvida a partir de Tambaqui (C. macropomum). Nesse sentido, foram realizadas as determinações para proteínas, lipídios, cinzas, umidade, carboidratos e valor calórico. Todas as análises foram feitas em triplicata. As proteínas foram determinadas pelo método de Kjeldahl, através da digestão, destilação e titulação da amostra para determinação de nitrogênio total. Para extração dos lipídios foram pesados aproximadamente $10 \mathrm{~g}$ de cada amostra e determinados pelo método de Bligh e Dyer (1959). O resíduo mineral fixo ou cinzas foram determinados por calcinação da amostra. Os carboidratos foram determinados por diferença. Com base nos dados laboratoriais e observação dos resultados obtidos verificou-se que a farinha de peixe de Tambaqui analisada aponta proteína de 70\%, gorduras de 5,5\%, cinzas de 3,9\%, umidade de 7,8\%, carboidratos de $12,8 \%$ e totalizando $380,7 \mathrm{kcal}$. Nas análises microbiológicas, todas as amostras avaliadas foram negativas tanto para Staphylococcus coagulase positivas, quanto para Salmonella sp., tornando o produto próprio para o consumo humano. Por fim, a partir da farinha foi possível manter as propriedades nutricionais do peixe Tambaqui $(C$. macropomum), sendo uma importante alternativa para o seu uso.
\end{abstract}

Palavras chave: Controle de qualidade, bromatologia, tecnologia de alimentos

\section{Development, physicochemical and microbiological evaluation of tambaqui flour, Colossoma macropomum (Cuvier, 1818)}

Abstract. Fish meat is the most consumed protein source of animal origin in the world, in
the North the consumption is around $135 \mathrm{~kg}$ per capita / year. Fishmeal, although little
known and used throughout the Brazilian territory, has been gradually discovered by
nutritionists and followers of healthy food. This work aims to evaluate the physico-
chemical and microbiological characteristics of a protein meal developed from Tambaqui
(C. macropomum). In this sense, determinations were made for proteins, lipids, ashes,
moisture, carbohydrates and caloric value. All analyzes were done in triplicate. Proteins
were determined by the Kjeldahl method, through digestion, distillation and titration of the
sample for determination of total nitrogen. For extraction of the lipids approximately $10 \mathrm{~g}$
of each sample were weighed and determined by the method of Bligh and Dyer (1959).
The fixed mineral residue or ashes were determined by calcination of the sample. 
Carbohydrates were determined by difference. Based on the laboratory data and observation of the obtained results it was verified that the fish meal of Tambaqui analyzed indicates protein of $70 \%$, fats of $5.5 \%$, ashes of $3.9 \%$, humidity of $7.8 \%$, carbohydrates of $12.8 \%$ and totaling $380.7 \mathrm{kcal}$. In the microbiological analyzes, all the samples evaluated were negative for both Staphylococcus coagulase positive and Salmonella sp., Making the product suitable for human consumption. Finally, from the flour, it was possible to maintain the nutritional properties of the Tambaqui fish (C. macropomum), being an important alternative for its use.

Keywords: Quality control, bromatology, food technology

\title{
Elaboración, evaluación fisicoquímica y microbiológica de la harina de Tambaqui, Colosoma macropomum (Cuvier, 1818)
}

\begin{abstract}
Resumen. La carne de pescado es la fuente proteica de origen animal más consumida en el mundo, en la región Norte el consumo es cerca de $135 \mathrm{~kg}$ per cápita / año. La harina de pescado, aun siendo poco conocida y utilizada en todo el territorio brasileño, viene siendo poco a poco descubierta por los nutricionistas y seguidores de alimentación saludable. Este trabajo tiene como objetivo evaluar las características fisicoquímicas y microbiológicas de una harina proteica desarrollada a partir de Tambaqui (C. macropomum). En ese sentido, se realizaron las determinaciones para proteínas, lípidos, cenizas, humedad, carbohidratos y valor calórico. Todos los análisis se realizaron en triplicada. Las proteínas fueron determinadas por el método de Kjeldahl, a través de la digestión, destilación y titulación de la muestra para determinación de nitrógeno total. Para la extracción de los lípidos se pesaron aproximadamente $10 \mathrm{~g}$ de cada muestra y determinados por el método de Bligh y Dyer (1959). El residuo mineral fijo o ceniza se determinó por calcinación de la muestra. Los carbohidratos se determinaron por diferencia. Con base en los datos de laboratorio y observación de los resultados obtenidos se verificó que la harina de pescado de Tambaqui analizada apunta proteína del 70\%, grasas del 5,5\%, cenizas del 3,9\%, humedad del 7,8\%, carbohidratos de $12,8 \%$ y totalizando $380,7 \mathrm{kcal}$. En los análisis microbiológicos, todas las muestras evaluadas fueron negativas tanto para Staphylococcus coagulasa positivas, como para Salmonella sp., Haciendo el producto propio para el consumo humano. Por último, a partir de la harina fue posible mantener las propiedades nutricionales del pescado Tambaqui (C. macropomum), siendo una importante alternativa para su uso.
\end{abstract}

Palabras clave: Control de calidad, bromatología, tecnología de alimentos

\section{Introdução}

A pesca extrativista e a produção aquícola representam um importante setor na produção alimentícia mundial (FAO, 2017). Todavia, no Brasil, a carne bovina ainda é a primeira escolha como fonte de proteína pela população, com exceção da região norte (Eiras et al., 2016; Guerrero et al., 2018), estas diferenças são atribuídas à fatores culturais (Costa et al., 2018b; Kirinus et al., 2014; Kirinus et al., 2013).

A ampla comercialização de pescados na região Norte, em diversas formas (fresco, salgado, seco e/ou seus derivados) representam um elevado valor comercial, cultural e econômico (Nunes et al., 2013). Estas diferenças regionais podem ser atribuídas a fatores limitantes, tais como o custo, facilidade de preparo, acesso e presença de tabus alimentares (Costa et al., 2018b). Todavia, quando comparado com países europeus ou latino-americanos, o consumo de peixes pela população brasileira pode ser considerado baixo (Lopes et al., 2016; Welch et al., 2002).

O Tambaqui (Colossoma macropomum) é um peixe de clima tropical, considerado como o maior Characiforme da região amazônica (Mourad, 2012). Está dentre as espécies mais consumidas no país, por este motivo é a espécie nativa mais produzida no Brasil. Na região Norte, essa produção chega a 65.000 toneladas de peixes (Campos et al., 2015). Dessa forma, com elevada oferta e preços baixos, este produto se torna altamente atrativo e competitivo no mercado. 
Como derivado de pescado, as farinhas proteicas são classificadas como subprodutos não comestíveis, elaborados a partir dos resíduos resultantes da manipulação (Brasil, 1997). No entanto, segundo Lourenço et al. (2011), é um produto tradicional da região amazônica e amplamente consumido. É produzido normalmente por peixes de baixo valor comercial, de forma artesanal e sem parâmetros bem definidos. Diante do exposto, o trabalho teve como objetivo avaliar as características físicoquímicas e microbiológicas de uma farinha proteica desenvolvida alternativamente a partir de filé de Tambaqui (C. macropomum).

\section{Material e métodos}

Peixes vivos foram adquiridos de tanques de Piscicultura da Fazenda Padre Cícero, no município de Porto Grande no Estado do Amapá. Após a despesca, foi feita a lavagem do peixe com água corrente e em seguida foi retirada as escamas e as vísceras. Em seguida foi feita a filetagem. A carne do peixe foi cortada em cubos de aproximadamente $3 \mathrm{~cm}$, armazenados em sacos plásticos estéreis e congelados em freezer comum com temperatura aproximada de $-12^{\circ} \mathrm{C}$. Após congelamento, foi feito o transporte para os Laboratórios de Físico-Química e Microbiologia do Instituto de Pesquisas Científicas e Tecnológicas do Estado do Amapá.

$\mathrm{Na}$ preparação da farinha, o peixe foi descongelado, pesado e levado à estufa por 24 horas a $70^{\circ} \mathrm{C}$ para a remoção da umidade. Após este período, o peixe foi prensado para retirada do óleo e foi levado novamente a estuda a $70^{\circ} \mathrm{C}$ por 46 horas. Após a secagem, realizou-se a trituração em liquidificador industrial por 3 minutos. Após a trituração da farinha, o produto foi envasado em sacos plásticos estéreis e armazenados a temperatura ambiente.

A composição físico-química da farinha foi realizada em triplicata, a metodologia seguiu a normativa do Instituto Adolfo Lutz (Brasil, 2008). O percentual de umidade foi feito em estufa da marca QUIMIS ${ }^{\circledR}$, modelo Q-317 B222, pelo método de secagem com circulação de ar, até atingir o peso constante. Para o teor proteico foi utilizado o Kjeldahl (AOAC, 2005). Para digestão, destilação e titulação da amostra para determinação de nitrogênio total, utilizando aparelho da marca TECNAL, Modelo TE 036/1. O resíduo mineral fixo ou cinzas foi determinado por calcinação em Mufla da marca QUIMIS ${ }^{\circledR}$, modelo Q-318 D21. O percentual de lipídios foi determinado pelo método de Bligh \& Dyer (1959).

A análise de coliforme termo tolerante iniciou com a determinação presuntiva, onde utilizada a técnica de tubos múltiplos, foi realizada uma diluição decimal seriada, e selecionadas três diluições adequadas e foram inoculadas em três tubos de ensaio contendo Caldo Lauril Sulfato Triptose (ACUMEDIA, 7142) para cada diluição, incubados a $37 \pm 1^{\circ} \mathrm{C} / 24 \pm 2 \mathrm{~h}$. Dos tubos positivos, foram transferidas alçadas carregadas para tubos contendo Caldo Escherichia coli - EC (ACUMEDIA, 7206), e foram incubados a $42 \pm 0,2^{\circ} \mathrm{C} / 24 \pm 2 \mathrm{~h}$. Após a incubação foi verificada a presença de crescimento com produção de gás, o número de tubos positivos é comparado com a tabela de Número Mais Provável (NMP para diluições decimais/g).

Para análise de Staphylococcus coagulase positiva (CP) foram selecionadas duas diluições para semeadura em superfície de placas de Ágar Baird-Parker (ACUMEDIA, 7112) e foram incubadas a 35$37^{\circ} \mathrm{C} / 45-48 \mathrm{~h}$. Após a incubação, foram contadas as colônias típicas do gênero e levadas para confirmação pelos testes de catalase em lâmina, coloração de Gram e coagulase em tubo. A quantificação ocorreu pelo cálculo de unidades formadores de colônias em função do número de colônias típicas, diluição inoculada e número de colônias confirmadas.

Para a detecção de Salmonella spp., 20g da amostra foi acrescentado em $280 \mathrm{~mL}$ de Caldo Lactosado (ACUMEDIA $7141 \mathrm{~A}$ ), sendo a incubação a $37 \pm 1^{\circ} \mathrm{C} / 24 \pm 2 \mathrm{~h}$ para o pré-enriquecimento. Passado $24 \mathrm{~h}$, foi transferido uma alíquota de $1 \mathrm{~mL}$ da cultura em Caldo Lactosado para o Caldo Rappaport Vassilidis Soja - RVS (MERCK MILLIPORE 107700), sendo incubado a $41 \pm 1^{\circ} \mathrm{C} / 24 \pm 2 \mathrm{~h}$. Dando seguimento a análise, foi realizada a etapa de plaqueamento seletivo, onde se utilizou os meios Ágar SalmonellaShigella - SS (MERCK MILLIPORE 107667) e Ágar Xilose Lisina Desoxicolato - XLD (BIOSYSTEMS 42618), ambos incubados em $37 \pm 1^{\circ} \mathrm{C} / 24 \pm 2 \mathrm{~h}$. As colônias típicas do gênero em estudo foram repicadas em Ágar Inclinado Tríplice Açúcar e ferro - TSI (NEOGEN 7162) e Ágar Lisina Ferro - LIA (HIMEDIA M377), incubados a $37 \pm 1^{\circ} \mathrm{C} / 24 \pm 2 \mathrm{~h}$. Das colônias com reações típicas na bioquímica preliminar (ágar TSI e LIA) realizou-se a sorologia com o soro somático polivalente segundo Brasil (2003). 


\section{Resultados e discussão}

A tabela 1 apresenta os resultados em valores médios das análises físico-químicas da farinha produzida a partir de filé de tambaqui comparado com o que já está descrito na literatura.

Tabela 1. Parâmetros físico-químicos da farinha a base de Tambaqui comparados com outros produtos

\begin{tabular}{lcccc}
\hline Parâmetros & Experimento & Piracuí1 $^{1}$ & Farinha de resíduo $^{2}$ & Tambaqui cru (Filé) $^{3}$ \\
\hline Umidade (\%) & $7,8 \pm 0,10$ & $13,61 \pm 1,25$ & 6,9 & 66,3 \\
Proteínas (\%) & $70 \pm 0,10$ & $66,7 \pm 6,51$ & 4,17 & 24,8 \\
Lipídeos Totais (\%) & $5,5 \pm 0,40$ & $9,58 \pm 0,17$ & 7,53 & 5,8 \\
Cinzas (\%) & $3,9 \pm 0,1$ & $10,2 \pm 0,6$ & 24,04 & 3,10 \\
Carboidrato (\%) & 12,8 & - & 57,36 & - \\
Valor Calórico Total (Kcal) & 380,7 & - & 314,44 & 151,4
\end{tabular}

${ }^{1}$ Farinha proteica (Piracuí) comercializado em feiras públicas (Silva Júnior et al., 2017); ${ }^{2}$ Farinha produzida a partir da pele de Tambaqui (Leitão \& Favacho, 2015); ${ }^{3}$ Filé de Tambaqui in natura (Aguiar, 1996).

De acordo com Visentainer et al. (2003), a umidade da musculatura de peixes pode variar entre 60 $85 \%$. No estudo de Aguiar (1996) foi relatado umidade de 66,3\% no filé de tambaqui cru. Na farinha produzida, a umidade foi de 7, $8 \pm 0,10 \%$, valor próximo ao encontrado por Leitão \& Favacho (2015), estando ambos abaixo de $12 \%$ como recomenda o Regulamento da Inspeção Industrial e Sanitária de Produtos de Origem Animal - RIISPOA (Brasil, 2017). Nos estudos desenvolvidos por Santos \& Freitas (2004) e Silva Júnior et al. (2017) o Piracuí produzido artesanalmente avaliado estava fora do padrão em ambos os trabalhos. Estas diferenças demonstram que a produção da farinha em ambiente controlado permite elaborar um produto que atenda a legislação vigente.

O valor proteico encontrado na farinha de tambaqui elaborada foi de $70 \pm 0,10 \%$, sendo superior ao valor proteico do filé de tambaqui cru (Aguiar, 1996), demonstrando que a farinha de tambaqui é uma excelente fonte de proteína animal quando comparado com outros autores. Silva Júnior et al. (2017) avaliando Piracuí comercializado em feiras públicas da cidade de Macapá, encontraram valor de 66,7 \pm $6,51 \%$. Na farinha elaborada por Leitão \& Favacho (2015) a partir da pele de Tambaqui, foi encontrado um valor bem inferior ao trabalho, de $4,17 \%$.

Para lipídeos, o valor encontrado no experimento foi de 5,5 $\pm 0,40 \%$. A carne de tambaqui in natura é considerada como semi-gorda, apresentando teor entre 5-15\% (Aguiar, 1996). O valor encontrado pode ser considerado baixo quando comparado com os 26,3\% encontrado por Franco et al. (2009). O processo de deslipidificação do pescado é importante na formulação do produto final, seja por solvente, ou por prensagem.

$\mathrm{Na}$ farinha proteica desenvolvida por Leitão \& Favacho (2015), o teor de cinzas ficou em cerca de $24,0 \%$. Souza et al. (2010) observaram na farinha proteica teor de cinzas de 3,4\%; enquanto que, Silva Júnior et al. (2017) encontraram valor de 10,0\%. O produto elaborado apresentou teor de 3,9\%, pois foi produzido a partir do filé do Tambaqui. Valores de cinzas baixos são resultados de processos de seleção da matéria prima que irá produzir a farinha. A única especificação para minerais existente na legislação brasileira, diz respeito a peixe salgado e seco, onde é determinado o limite máximo de 25\% (Brasil, 2017).

Os carboidratos encontrados no produto desenvolvido estavam abaixo do encontrado por Leitão \& Favacho (2015). O valor calórico estava semelhante. Os aspectos microbiológicos são apresentados e comparados com outros trabalhos na tabela 2.

A contagem de coliformes a $45^{\circ} \mathrm{C}$ e ausência de Salmonella do produto avaliado foi semelhante aquela encontrada por Leitão \& Favacho (2015) e Silva Júnior et al. (2017), assim como Nunes et al. (2013) avaliando Piracuí comercializado em Belém, Pará. Estes resultados foram relacionados à baixa atividade de água que o Piracuí normalmente apresenta; o que vem dificultar o crescimento de microrganismos. Lourenço et al. (2011) avaliando o tempo de prateleira do Piracuí embalado a vácuo, permaneceu com contagens de $<1,0 \times 10^{1} \mathrm{NMP} / \mathrm{g}$ para coliformes a $45^{\circ} \mathrm{C}$ e ausência de Salmonella spp. em 90 dias da preparação e embalagem do produto. 
Tabela 2. Parâmetros microbiológicos da farinha a base de Tambaqui comparados com outros trabalhos.

\begin{tabular}{lcccc}
\hline Parâmetros & Experimento & $\begin{array}{c}\text { Silva Júnior et al. } \\
(2017)\end{array}$ & $\begin{array}{c}\text { Leitão \& Favacho } \\
(2015)\end{array}$ & $\begin{array}{c}\text { Lourenço et al. } \\
(2011)\end{array}$ \\
\hline Coliformes a $45^{\circ} \mathrm{C},(\mathrm{NMP} / \mathrm{g})$ & $<3,0$ & $<3,0$ & $<3,0$ & $<1,0 \times 10^{1}$ \\
Staphylococcus $\mathrm{CP}(\mathrm{UFC} / \mathrm{g})$ & Ausente & $1,3 \times 10^{4}$ & $4,11 \times 10^{3}$ & $<1,0 \times 10^{1}$ \\
Salmonnella spp. & Ausente & Ausente & Ausente & Ausente \\
\hline
\end{tabular}

O Staphylococcus coagulase positiva, na farinha desenvolvida, estava ausente. O que difere dos resultados encontrados por Leitão \& Favacho (2015) e Silva Júnior et al. (2017), onde em ambos os estudos foram evidenciados contagens de $1,3 \times 10^{4} \mathrm{e} 4,11 \times 10^{3} \mathrm{UFC} / \mathrm{g}$ respectivamente. A contagem deste microrganismo evidencia falhas higiênicas sanitárias durante a produção. Vale ressaltar que este microrganismos é comum na comercialização com falhas sanitárias de produtos pesqueiros (Costa et al., 2018a; Reis et al., 2017; Silva Júnior et al., 2015a; Silva Júnior et al., 2015b; Viana et al., 2016).

A farinha proteica é uma importante forma de conservação de peixes, pois são os alimentos de origem animal com maior probabilidade de deterioração devido suas características intrínsecas (Silva et al., 2017). Silva et al. (2017) ainda destacam que devido estes fatores, há a necessidade de se fazer uso de técnicas de conservação nos produtos pesqueiros.

\section{Conclusão}

A farinha de peixe é um produto amplamente consumido principalmente na região Norte. Suas características peculiares têm feito com que ele ganhasse cada vez mais espaço na culinária brasileira. Todavia, as altas contaminações do Piracuí comercializado a granel ou em embalagens inapropriadas em feiras públicas associado às falhas higiênico-sanitárias na cadeia produtiva e a ausência de legislação específica para este produto torna importante o desenvolvimento de farinhas de peixes alternativas que possuam qualidade nutricional e atendam critérios microbiológicos mínimos para o seu consumo. A farinha desenvolvida neste trabalho se mostrou uma excelente fonte proteica, com baixa umidade e teor de lipídeos, e atende todos os critérios microbiológicos se comparados com pescado seco e salgado sendo então uma alternativa para o uso do tambaqui.

\section{Referências bibliográficas}

Aguiar, J. P. L. (1996). Tabela de Composição de Alimentos da Amazônia. Acta Amazônica, 26(1/2):121-126.

AOAC. (2005). - Association Official Analytical Chemist (2005) (Official Methods of Analysis (18th ed.) ed.). Gaitherburg, Maryland, USA: AOAC.

Bligh, E. G. \& Dyer, W. J. (1959). A rapid method of total lipid extraction and purification. Canadian Journal of Biochemistry and Physiology, 37(8):911-917.

Brasil. (2008). Agência Nacional de Vigilância Sanitária. Métodos Físico-químicos para Análises de Alimentos. Instituto Adolfo Lutz. $4^{a}$ Edição. Brasília. Cap. IV e XVI, p.83-158.

Brasil. (2003). Ministério da Agricultura, Pecuária e do Abastecimento. Secretaria de Defesa Agropecuária. Instrução Normativa n ${ }^{\circ}$ 62, de 26 de agosto de 2003. Oficializa os Métodos Analíticos Oficiais para Análises Microbiológicas para Controle de Produtos de Origem Animal e Água. Diário Oficial [da] República Federativa do Brasil, Brasília, 18 de setembro de 2003. Disponível em: http://extranet.agricultura.gov.br/sislegis-

consulta/consultarLegislacao.do?operacao=visualizar\&id=285. Acesso em: 08/08/2017.

Brasil. (2017). Ministério da Agricultura, Pecuária e Abastecimento. Secretaria de Defesa Agropecuária. Decreto $n^{\circ} 3.691$ de 29 de março de 1952, alterado pelos Decretos $n^{\circ} 1255$ de 25 de junho de 1962, 1236 de 02 de setembro 1994, 1812 de 08 de fevereiro de 1996, 2.244 de 04 de junho de 1997 e 9.013 de 29 de março de 2017. Aprova o Regulamento da Inspeção Industrial e Sanitária de Produtos de Origem Animal (RIISPOA), Brasília, DF. Diário Oficial [da] República Federativa do Brasil. Brasília, DF, 29 mar. 2017, Seção 1. Disponível em: http://www.agricultura.gov.br/arq_editor/file/Aniamal/MercadoInterno/Requisitos/RegulamentoIns pecaoIndustrial.pdf. Acesso em: 15/06/2017. 
Brasil. (1997). Ministério da Agricultura, Pecuária e Abastecimento. Secretaria de Defesa Agropecuária. Decreto $\mathrm{n}^{\circ} 3.691$ de 29 de março de 1952, alterado pelos Decretos $\mathrm{n}^{\circ} 1255$ de 25 de junho de 1962, 1236 de 02 de setembro 1994, 1812 de 08 de fevereiro de 1996 e 2.244 de 04 de junho de 1997. Aprova o Regulamento da Inspeção Industrial e Sanitária de Produtos de Origem Animal (RIISPOA), Brasília, DF, 1997. Diário Oficial [da] República Federativa do Brasil. Brasília, DF, 05 jun. 1997, Seção 1.1 Disponível em: http://www.agricultura.gov.br/arq_editor/file/Aniamal/MercadoInterno/Requisitos/RegulamentoIns pecaoIndustrial.pdf. Acesso em: 08/08/2017.

Brasil. (2001). Ministério da Saúde, Agência Nacional de Vigilância Sanitária (ANVISA). Resolução RDC $\mathrm{n}^{\circ} 12$, de 2 de janeiro de 2001. Regulamento técnico sobre padrões microbiológicos para alimentos. Diário Oficial [da] República Federativa do Brasil. Brasília, DF. Disponível em: http://www.anvisa.gov.br/legis/resol/12_01rdc.htm. Acesso em: 12/05/2017.

Campos, J. L., Ono, E. A. \& Istchuk, P. I. (2015). A Cadeia de rodução e o preço do Tambaqui. Panorama da Aqüicultura, 25(149):42-45.

Costa, A. L. P., Nascimento, J. F. \& Silva Júnior, A. C. S. (2018a). Perfil de resistência de Staphylococcus aureus isolados de pescada amarela (Cynoscion acoupa) comercializada em feira pública. PUBVET, 12(5):1-6.

Costa, T. V., Silva, R. R. S., Souza, J. L., Batalha, O. S. \& Hoshiba, M. A. (2018b). Aspectos do consumo e comércio de pescado em Parintins. Boletim do Instituto de Pesca, 39(1):63-75.

Eiras, C. E., Ornaghi, M. G., Valero, M. V., Rivaroli, D. C., Guerrero, A. \& Prado, I. N. (2016). How does the dietary cottonseed hull affect the carcass characteristics and meat quality of young bulls finished in a high-concentrate diet? Acta Scientiarum. Animal Sciences, 38(3):301-310.

FAO. (2017). Statistical Yearbook (Vol. 1). Rome, Italy: Food and Agriculture Organization of the United Nations.

Franco, M. L. R. S., Godoy, L. C., Souza, N. E., Stevanato, F. B., Franco, N. P. \& Visentainer, J. V. (2009). Aproveitamento de carcaças de pacu (Piaractus mesopotamicus). Revista Aqüicultura \& Pesca, 3952-58.

Guerrero, A., Rivaroli, D. C., Sañudo, C., Campo, M. M., Valero, M. V., Jorge, A. M. \& Prado, I. N. (2018). Consumer acceptability of beef from two sexes supplemented with essential oil mix. Animal Production Science, 58(9):1700-1707. doi: http://dix.doi.org/10.1071/AN15306.

Kirinus, J. K., C., S., Fruet, A. P. B., Dörr, A. C. \& Nörnberg, J. L. (2014). Caracterización socieconómica de consumidores con elevada ingesta de carne bovina. Enciclopédia Biosfera, 10(19):2830-2848.

Kirinus, J. K., Fruet, A. P. B., Klinger, A. C. K., Dörr, A. C. \& Nörnberg, J. L. (2013). Relação entre faixas de renda e o perfil dos consumidores de carne bovina da região sul do Brasil. Revista Monografias Ambientais, 12(12):2776-2784.

Leitão, B. R. G. S. \& Favacho, M. C. (2015). Elaboração e avaliação nutricional da farinha da pele do Tambaqui (Colossoma macropomum) e utilização em produtos alimentícios. Nexus-Revista de Extensão do IFAM, 1(2):65-70.

Lopes, I. G., Oliveira, R. G. \& Ramos, F. M. (2016). Perfil do consumo de peixes pela população brasileira. Biota Amazonia (Biote Amazonie, Biota Amazonia, Amazonian Biota), 6(2):62-65.

Lourenço, L. F. H., Santos, D. C., Ribeiro, S. C. A., Almeida, H. \& Araujo, E. A. F. (2011). Study of adsorption isotherm and microbiological quality of fish meal type "piracuí" of Acari-Bodo (Liposarcus pardalis, Castelnau, 1855). Procedia Food Science, 1455-462.

Mourad, N. M. N. (2012). Crescimento ponderal e morfométrico do pacu Piaractus mesopotamicus, tambaqui Colossoma macropomum e seus híbridos da primavera ao inverno. Master of Science, Universidade Federal de Lavras, Lavras.

Nunes, E. S. C. L., Bittencourt, R. H. F. P. M., Silva, M. C., Mársico, E. T. \& Franco, R. M. (2013). Avaliação da qualidade do camarão salgado seco (aviú) e da farinha de peixe (piracuí) comercializados em mercados varejistas da cidade de Belém, Pará. Revista do Instituto Adolfo Lutz, 72(2):147-154. 
Reis, D. H. C., Meneguelli, M., Muniz, I. M., Caetano, A. R., Araújo, K. F. \& Osowski, A. (2017). Avaliação do perfil microbiológico do peixe Pseudoplatystoma corruscans e Colossoma macropomum (pintado e tambaqui), comercializado no município de Rolim de Moura, tendo em foco a saúde pública. Revista Brasileira de Ciências da Amazônia, 6(1):21-28.

Santos, J. R. C. \& Freitas, J. A. (2004). Características e qualidade de um produto derivado de peixe denominado "Piracuí". Revista de Ciências Agrárias Amazonian Journal of Agricultural and Environmental Sciences, 4147-56.

Silva, A. T. F. S., Rocha, P. G. G., Fonseca Filho, L. B., Costa, C. A., Nascimento, J. C. S. N. \& Carvalho Neto, P. M. (2017). Alterações microbianas dos produtos de pescados curados: Revisão. PUBVET, 11(1):658-661.

Silva Júnior, A. C. S., Silva, A. C. S., Barbosa, F. H. F., Proietti Junior, A. A., Palha, S. E. M. \& Emin, E. T. (2015a). Avaliação microbiológica de pescada branca (Cynoscion spp) comercializada na feira do pescado, Macapá AP. Higiene Alimentar, 29(246/247):108-112.

Silva Júnior, A. C. S., Silva, A. d. S. S., Brito, T. P. \& Ferreira, L. R. (2015b). Ocorrência de Staphylococcus coagulase positiva e coliformes termotolerantes em Jaraqui, Semaprochilodus brama (Valenciennes, 1850) comercializado na feira do pescado, Macapá-AP. Biota Amazônia (Biote Amazonie, Biota Amazonia, Amazonian Biota), 5(1):32-36.

Silva Júnior, A. C. S., Silva, A. d. S. S., Soares, N. R. M., Moraes, G. R., Sousa, C. M. \& Nascimento, J. F. (2017). Caracterização físico-química e avaliação microbiológica de concentrado proteico de peixe (Piracuí) comercializado em feiras livres da Cidade de Macapá-AP. Biota Amazônia (Biote Amazonie, Biota Amazonia, Amazonian Biota), 7(3):33-36.

Souza, J. F., Bittencout, N. N., Gomes, C. S., Oliveira, J. K., Santos, R. M., Reis, I. A. O., . . Narain, N. (2010). Desenvolvimento e caracterização físico-química e sensorial de nuggets formulados com concentrado protéico de pescado-MARINE BEEF. Scientia Plena, 6(3):1-4.

Viana, I. C. L. d. A., Valiatti, T. B., Sobral, F. O. S., Romão, N. F., Fonseca, C. X. \& Oliveira, U. A. (2016). Análise microbiológica do tambaqui (Colossoma macropomum) comercializado na feira municipal de Ariquemes, Estado de Rondônia, Brasil. Revista Pan-Amazônica de Saúde, 7(2):67-73.

Visentainer, J. V., Matsushita, M., Souza, N. E., Catharino, R. R. \& Franco, M. R. B. (2003). Composição química e de ácidos graxos em tilápias (Oreochromis niloticus) submetidas à dieta prolongada. Revista Nacional da Carne, 3109-112.

Welch, A. A., Lund, E., Amiano, P., Dorronsoro, M., Brustad, M., Kumle, M., . . Jansson, J. (2002). Variability of fish consumption within the 10 European countries participating in the European Investigation into Cancer and Nutrition (EPIC) study. Public Health Nutrition, 5(6b):1273-1285.

Recebido: 15 de junho, 2019.

Aprovado: 13 de julho, 2019.

Publicado: 9 de setembro, 2019.

Licenciamento: Este artigo é publicado na modalidade Acesso Aberto sob a licença Creative Commons Atribuição 4.0 (CC-BY 4.0), a qual permite uso irrestrito, distribuição, reprodução em qualquer meio, desde que o autor e a fonte sejam devidamente creditados. 